\title{
Pemilihan Green Supplier Berdasarkan Fuzzy AHP Dengan Metode Fuzzy Topsis
}

\author{
Akhmad Ghiffary Budianto \\ Jurusan Teknik Industri, Fakultas Teknik, Universitas Muhammadiyah Malang \\ Jl. Raya Tlogomas No. 246, Malang, Jawa Timur 65144 \\ surel: ghiffaryb04@gmail.com
}

\begin{abstract}
PT. Petrokimia Gresik is a company producing fertilizer with raw material reactive chemicals. In the production process required adjuvant to speed up the process. On the other hand, the company also wants to realize its mission to the environment in accordance with goverment regulations. So that the company's activities will reach a point of balance between the economy an the environment. The goal of this research is to help the company in determining the criteria and sub-criteria are influential in selecting green suppliers with Fuzzy AHP method, and helping to choose the best alternative green supplier with Fuzzy TOPSIS method. There are 9 criteria and 19 sub-criteria and 4 alternative supplier in this study. Based on the calculation method of Fuzzy AHP, the criteria that affect are the quality and environmental management system, whle for sub criteria are green image and the PPM levels. Based on the calculation method of Fuzzy TOPSIS obtained the best alternative solution for the company is supplier 1 from 4 alternative supplier
\end{abstract}

Keywords: Selection, Green Supplier, Fuzzy AHP, Fuzzy TOPSIS, MCDM.

\begin{abstract}
Abstrak
PT. Petrokimia Gresik merupakan perusahaan yang memproduksi pupuk dengan bahan baku zat kimia reaktif. Dalam proses produksinya diperlukan bahan penolong untuk mempercepat suatu proses. Disisi lain perusahaan juga ingin mewujudkan misi terhadap lingkungan sesuai dengan regulasi pemerintah. Sehingga aktivitas perusahaan akan mencapai titik keseimbangan antara ekonomi dan lingkungan. Tujuan yang ingin dicapai dalam penelitian ini yaitu membantu perusahaan dalam menentukan kriteria dan sub kriteria yang berpengaruh dalam pemilihan green supplier dengan metode Fuzzy AHP serta membantu perusahaan memilih alternatif green supplier terbaik dengan metode Fuzzy TOPSIS. Terdapat 9 kriteria dan 19 sub kriteria serta 4 alternatif supplier dalam penelitian ini. Berdasarkan hasil perhitungan metode Fuzzy AHP, kriteria yang berpengaruh yaitu kualitas dan sistem manajemen lingkungan, sedangkan untuk sub kriteria yaitu green image dan kadar PPM. Dari metode Fuzzy TOPSIS didaptakan solusi alternatif terbaik bagi perusahaan yaitu supplier ke-1 dari empat alternatif.
\end{abstract}

Kata Kunci: Pemilihan, Green Supplier, Fuzzy AHP, Fuzzy TOPSIS, MCDM.

\section{Pendahuluan}

Sistem rantai pasok yang digunakan di dunia industri sekarang cenderung menggunakan hubungan dengan supplier dalam jangka waktu yang panjang dan percaya penuh (trust) pada supplier tersebut. Supplier adalah pihak yang menyediakan input, berupa barang yang dibutuhkan dalam kegiatan produksi[1]. Sedangkan Green supplier adalah untuk membantu perusahaan mencapai keseimbangan antara kinerja ekonomi dan lingkungan, mengurangi dampak dari produk dan jasa di lingkungan dan menumbuhkan citra lingkungan. Hal ini bertujuan unuk mengurangi dampak negatif pada lingkungan[2]. 
PT. Petrokimia Gresik adalah salah satu pabrik di Indonesia yang memproduksi pupuk. Pada proses produksi diperlukan adanya supplier dari bahan baku dan bahan penolong. Proses pemilihan supplier dari bahan baku dan bahan penolong sama pentingnya. Dalam penelitian ini, peneliti memfokuskan pada pemilihan supplier bahan penolong, yaitu bahan penolong untuk Cooling Water Treatment system (CWT).

Hal ini dilakukan karena supplier bahan baku utama hanya sedikit dan tidak perlu diseleksi, sedangkan untuk supplier bahan penolong jumlahnya banyak dan perlu melewati proses seleksi sesuai kriteria yang telah ditetapkan oleh perusahaan. Dalam hal ini perusahaan memiliki kriteria untuk menyeleksi calon supplier dilihat dari mutu produk, delivery dan harga. Adapun perusahaan juga mempunyai misi terhadap lingkungan yaitu sesuai dengan regulasi pemerintah terkait dengan kebijakan industri nasional. Untuk mewujudkan misi tersebut, maka diperlukan strategi yang tepat dalam pencapaiannya. Salah satu strategi ialah integrasi green supply chain yaitu dengan melakukan penyeleksian green supplier sesuai dengan kriteria ekonomi dan lingkungan yang bertujuan untuk menjamin kelancaran proses produksi dan meningkatkan green image dimata masyarakat.

Berdasarkan uraian diatas, pemilihan green supplier yang tepat merupakan solusi untuk dapat memenuhi permintaan secara tepat waktu, jumlah dan kualitas tanpa mengesampingkan masalah lingkungan yang ditimbulkan dari proses produksi. Dalam penelitian ini, peneliti menggunakan konsep dari Multi Attribute Decision Making (MADM), yaitu Fuzzy AHP dan Fuzzy TOPSIS. Penggunaan metode fuzzy didasarkan pada konsepnya yang dapat mengakomodir penilaian dengan nilai yang saling berdekatan (kabur)[3]. Sedangkan metode AHP dapat memberikan bobot yang sesuai dengan penilaian decision makers dengan cara membandingkan satu kriteria dengan kriteria lainnya atau dengan kata lain AHP dapat menyelesaikan suatu masalah yang kompleks dengan menyusunnya menjadi sebuah hierarki[4]. Selanjutnya dari kriteria yang sudah terbobot akan dilakukan perhitungan performansi total dari setiap calon supplier dengan metode Fuzzy TOPSIS. Metode TOPSIS dapat memberikan solusi mendekati terbaik berdasarkan perhitungan preferensi alternatifnya sehingga lebih presisi dan konsisten dalam memberikan penilaian dari decision makers tanpa membandingkan terlebih dahulu antar supplier satu dengan supplier yang lainnya. Untuk kriteria yang digunakan diambil dari jurnal Hashemi pada tahun 2015 yang bertema pemilihan green supplier[5]. Pemilihan konsep dari kriteria green supplier tersebut dikarenakan kesesuaian dengan kondisi lapangan, regulasi pemerintah dan jenis kriteria yang beragam.

Tujuan utama dari penelitian ini adalah untuk menentukan urutan prioritas kriteria pemilihan green supplier berdasarkan teori green supply chain, regulasi pemerintah dan keadaan lapangan di pabrik sehingga keputusan yang dibuat dapat memberikan keuntungan yang optimal bagi perusahaan dan untuk mengetahui supplier mana yang menjadi green supplier terbaik berdasarkan 9 kriteria dan 19 sub kriteria yang ada. Agar tujuan penelitian ini dapat tercapai dengan baik, maka dilakukan penggabungan dari tiga metode dalam proses analisisnya. Ketiga metode tersebut adalah Logika Fuzzy untuk mengurangi faktor subjektivitas penilaian, Analitical Hierarchy Process (AHP) untuk menentukan bobot dari kriteria dan sub kriteria, dan Technique for Order Preference by Similarity to Ideal Solution (TOPSIS) untuk melakukan perangkingan pada sub kriteria akhir sehingga dapat menentukan supplier mana yang merupakan green supplier terbaik bagi perusahaan.

\section{Metode Penelitian}


Tahapan yang dilakukan dalam penelitian ini dimulai dengan perhitungan Fuzzy AHP untuk kriteria dan sub kriteria.. Inputan yang berasal dari hasil penilaian pada kuisoner yang diisi oleh tim pengadaan yang terdiri dari 3 staff ahli pengadaan. Kriteria dan sub kriteria didapatkan dari hasil brainstorming yang berdasarkan pada teori green supply chain, regulasi pemerintah dan kondisi lapangan. Dari hasil penilaian pada kuisoner, dilakukan uji konsistensi. Apabila hasil dari uji konsisten sudah konsisten, maka dapat dilanjutkan ke tahap pengubahan bilangan crisp ke bilangan fuzzy, apabila tidak konsisten maka dilakukan penilaian ulang. Setelah pengubahan bilangan Triangular FuzzyNumber, maka dapat dilakukan perhitungan bobot kriteria dan sub kriteria sesuai dengan algoritma Fuzzy AHP yang diperkenalkan oleh Chang[6]. Hasil perhitungan bobot kriteria akan dikalikan dengan hasil perhitungan bobot sub kriteria, sehingga didapatkan nilai akhir dari bobot sub kriteria. Nilai akhir dari bobot sub kriteria ini yang akan menjadi dasar penilaian performansi calon supplier.

Pada tahapan selanjutnya, melakukan pengukuran performansi keseluruhan dari beberapa alternatif dengan metode Fuzzy TOPSIS yang diperkenalkan oleh Chen \& Hwang[7], yang dimulai dari pengubahan nilai crisp dari kuisoner ke nilai Triangular Fuzzy Number. Pada matriks berbentuk TFN akan dinormalisasikan ke tipe benefit. Hasil normalisasi akan dikalikan dengan nilai bobot akhir dari sub kriteria sehingga terbentuk matriks normalisasi terbobot. Langkah berikutnya yaitu menentukan fuzy solusi ideal positif dan ideal negatif dari matriks ternomalisasi terbobot. Setelah itu menghitung jarak antara nilai setiap alternatif dengan matriks solusi ideal positif dan ideal negatif. Dari perhitungan jarak solusi ideal positif dan ideal negatif dapat melakukan perhitungan koefisien kedekatan setiap alternatif. Koefisien kedekatan setiap alternatif digunakan sebagai perangkingan alternatif. Nilai koefisien kedekatan terbesar merupakan solusi alternatif terbaik dengan ranking 1.

\section{Hasil dan Pembahasan}

Berdasarkan hasil wawancara dan brainstorming kemudian disusun menjadi struktur hierarki (lihat gambar 1).

Langkah pada metode Fuzzy AHP sebagai berikut :

Hasil uji konsistensi penilaian untuk pembobotan kriteria dan sub kriteria

Tabel 1 Hasil Uji Konsistensi Metode AHP untuk kriteria Pada Setiap Responden

\begin{tabular}{cccc}
\hline Kuisioner Responden & CI & CR & Keterangan \\
\hline Responden Ke-1 & 0,12 & 0,079 & Konsisten \\
Responden Ke-2 & 0,13 & 0,09 & Konsisten \\
Responden Ke-3 & 0,13 & 0,09 & Konsisten
\end{tabular}




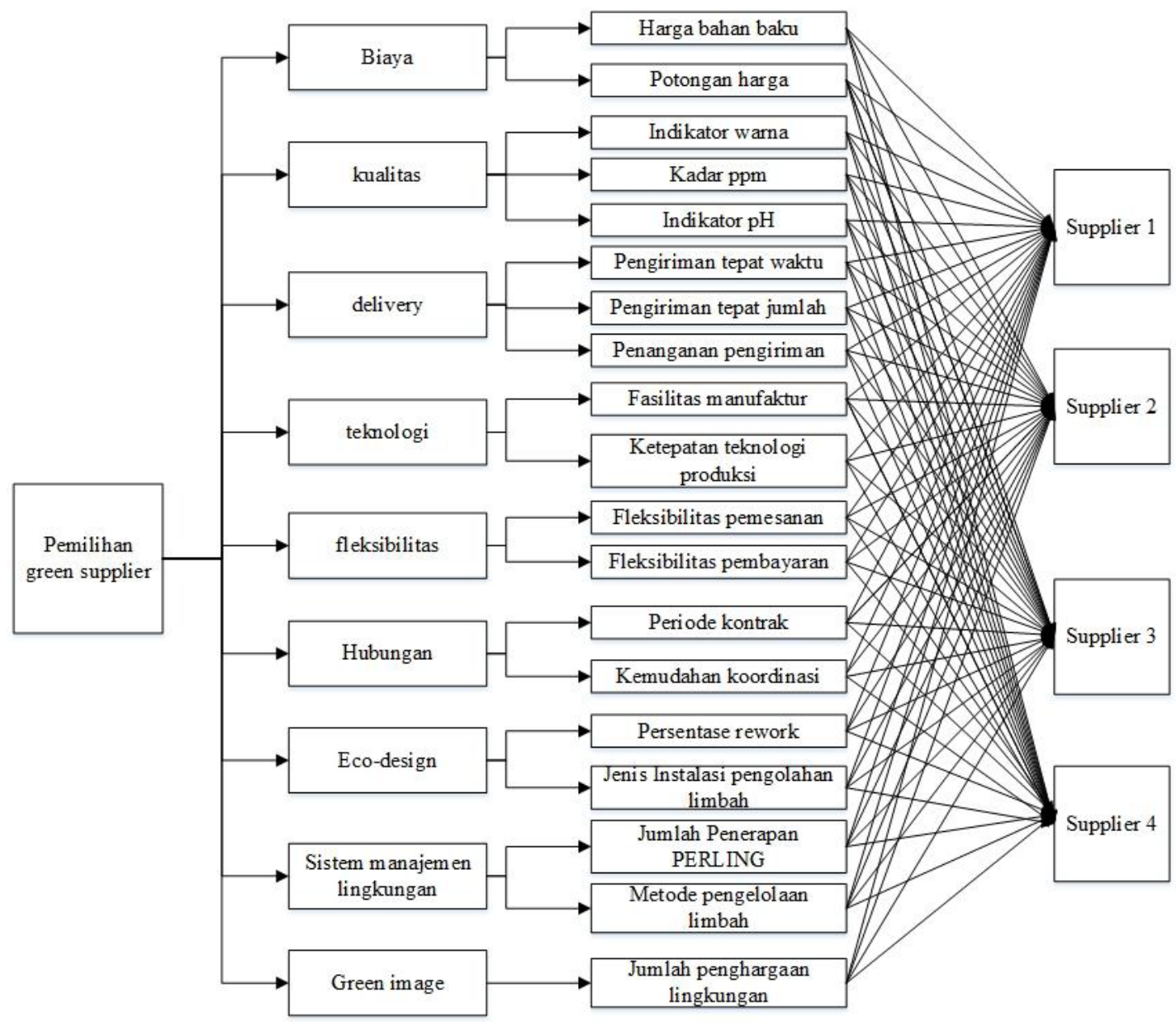

Gambar 1 Struktur Hierarki

Tabel 2 Hasil Uji Konsistensi Penilaian Sub Kriteria dari Ketiga Responden

\begin{tabular}{|c|c|c|c|c|c|c|c|c|c|c|c|}
\hline \multirow{2}{*}{ Sub Kriteria } & \multirow{2}{*}{$\mathrm{n}$} & \multirow{2}{*}{$\mathrm{Ri}$} & \multicolumn{3}{|c|}{ Responden 1} & \multicolumn{3}{|c|}{ Responden 2} & \multicolumn{3}{|c|}{ Responden 3} \\
\hline & & & $\mathrm{Ci}$ & $\mathrm{CR}$ & Ket & $\mathrm{Ci}$ & $\mathrm{CR}$ & Ket & $\mathrm{Ci}$ & $\mathrm{CR}$ & Ket \\
\hline Biaya & 2 & 0 & 0 & 0 & Konsisten & 0 & 0 & Konsisten & 0 & 0 & Konsisten \\
\hline Kualitas & 3 & 0,58 & 0 & 0 & Konsisten & 0,03 & 0,05 & Konsisten & 0,03 & 0,05 & Konsisten \\
\hline Delivery & 3 & 0,58 & 0 & 0 & Konsisten & 0,03 & 0,05 & Konsisten & 0,04 & 0,06 & Konsisten \\
\hline Teknologi & 2 & 0 & 0 & 0 & Konsisten & 0 & 0 & Konsisten & 0 & 0 & Konsisten \\
\hline Fleksibilitas & 2 & 0 & 0 & 0 & Konsisten & 0 & 0 & Konsisten & 0 & 0 & Konsisten \\
\hline Hubungan & 2 & 0 & 0 & 0 & Konsisten & 0 & 0 & Konsisten & 0 & 0 & Konsisten \\
\hline Eco-Design & 2 & 0 & 0 & 0 & Konsisten & 0 & 0 & Konsisten & 0 & 0 & Konsisten \\
\hline $\begin{array}{l}\text { Sistem Manajemen } \\
\text { Lingkungan }\end{array}$ & 2 & 0 & 0 & 0 & Konsisten & 0 & 0 & Konsisten & 0 & 0 & Konsisten \\
\hline
\end{tabular}

1) Menormalisasi matriks perbandingan. Normalisasi bertujuan untuk menyetarakan nilai dari matriks perbandingan berpasangan itu sendiri dengan angka minimal $=0$ dan 
maksimal $=1$. Karena ada 3 decision makers dalam penelitian ini, maka terlebih dahulu dilakukan rata-rata dengan metode mean arithmatic. Mean aritmatic yaitu merataratakan beberapa nilai sesuai dengan jumlah $\mathrm{n}$.

Mean Arithmatic : $\bar{x}_{l}=\frac{x_{1}+x_{2}+\ldots+x_{n}}{n}$

2) Melakukan perhitungan total nilai lower middle, dan upper. Nilai dari total L, M, dan U berfungsi untuk menentukan nilai dari sintesis fuzzy tiap kriteria. Untuk rekapitulasi nilai L, M, dan U

3) Melakukan perbandingan nilai derajat probabilitas

$V\left(M_{2} \geq M_{1}\right)=\left\{\begin{array}{c}1, \text { jika } m_{2} \geq m_{1} \\ 0, \text { jika } l_{1} \geq u_{2} \\ \frac{\left(l_{1}-u_{2}\right)}{\left(m_{2}-u_{2}\right)-\left(m_{1}-l_{1}\right)}, \text { yang lainnya }\end{array}\right.$

4) Melakukan Defuzzyfikasi dari nilai derajat perbandingan. Hasil defuzzyfikasi nilai perbandingan sebagai berikut :

$$
W^{\prime}=(0.583,1,0.609,0.191,0.599,0,0.329,0.7,0.591)
$$

Nilai tersebut lalu dinormalisasikan sehingga hasil bobot dari kriteria sebagai berikut: $W=(0.126,0.216,0.132,0.042,0.135,0,0.071,0.151,0.128)$

Apabila selesai pada tahapan perhitungan bobot kriteria, maka dilanjutkan untuk perhitungan bobot sub kriteria. Penilaian untuk sub kriteria juga melalui kuisoneryang diisi oleh decision makers. Sub kriteria merupakan turunan dari kriteria, yang lebih memperjelas kriteria yang digunakan dalam pemilihan green supplier. Perhitungan dilakukan dengan cara yang sama seperti perhitungan bobot pada kriteria.

5) Hasil algoritma fuzzy AHP didapatkan nilai defuzzyfikasi dari sub kriteria sebagai berikut :

$$
\begin{aligned}
& W b^{\prime}=(0.459,1) \\
& W k^{\prime}=(0.302,1.0 .802) \\
& W t^{\prime}=(0.429,1) \\
& W f^{\prime}=(0.819,1) \\
& W d^{\prime}=(0.877,0.658,0.302) \\
& W h^{\prime}=(0.205,1) \\
& W e^{\prime}=(0.429,1) \\
& W s^{\prime}=(0.429,1)
\end{aligned}
$$

Hasil dari nilai defuzzyfikasi selanjutnya dinormalisasikan sehingga didapatkan bobot sub kriteria sebagai berikut :

$$
\begin{aligned}
& W b=(0.314,0.686) \\
& W k=(0.049,0.528 .0 .423) \\
& W t=(0.3,0.7) \\
& W f=(0.45,0.55) \\
& W d=(0.198,0.487,0.315) \\
& W h=(0.17,0.83) \\
& W e=(0.3,0.7) \\
& W s=(0.3,0.7)
\end{aligned}
$$


Hasil akhir dari perhitungan fuzzy AHP untuk menentukan bobot kriteria dan sub kriteria adalah sebagai berikut

Tabel 3 Hasil Nilai Bobot Akhir dari Setiap Sub Kriteria

\begin{tabular}{|c|c|c|c|c|}
\hline Kriteria & Bobot & Sub Kriteria & Bobot & Bobot Akhir \\
\hline \multirow{4}{*}{ Harga } & \multirow{4}{*}{0,126} & Harga Bahan Baku & 0,314 & 0,040 \\
\hline & & Potongan Harga & 0,686 & 0,086 \\
\hline & & Indikator Warna & 0,049 & 0,011 \\
\hline & & Kadar Zat PPM & 0,528 & 0,114 \\
\hline \multirow{2}{*}{ Kualitas } & \multirow{2}{*}{0,216} & Indikator $\mathrm{pH}$ & 0,423 & 0,091 \\
\hline & & Pengiriman Tepat Waktu & 0,198 & 0,026 \\
\hline \multirow{2}{*}{ Delivery } & \multirow{2}{*}{0,132} & Pengiriman Tepat Jumlah & 0,487 & 0,064 \\
\hline & & Penanganan Pengiriman & 0,315 & 0,041 \\
\hline \multirow[b]{2}{*}{ Teknologi } & \multirow{2}{*}{0,042} & Fasilitas Manufaktur & 0,300 & 0,013 \\
\hline & & Ketepatan Teknologi Produksi & 0,700 & 0,029 \\
\hline \multirow{2}{*}{ Fleksibilitas } & \multirow{2}{*}{0,135} & Fleksibilitas Pemesanan & 0,450 & 0,061 \\
\hline & & Fleksibilitas Pembayaran & 0,550 & 0,074 \\
\hline \multirow[b]{2}{*}{ Hubungan } & \multirow{2}{*}{0,000} & Periode Kontrak & 0,170 & 0,000 \\
\hline & & Kemudahan Koordinasi & 0,830 & 0,000 \\
\hline \multirow[b]{2}{*}{ Eco-Design } & \multirow{2}{*}{0,071} & Presentase Rework & 0,300 & 0,021 \\
\hline & & Jenis Instalasi Pengolahan Limbah & 0,700 & 0,050 \\
\hline \multirow{2}{*}{ Sistem Manajemen } & \multirow{2}{*}{0,151} & Jumlah Penerapan PERLING & 0,300 & 0,045 \\
\hline & & Metode Pengelolaan Limbah & 0,700 & 0,106 \\
\hline Green Image & 0,128 & Jumlah Penghargaan Lingkungan & 0,100 & 0,128 \\
\hline Total & 1 & Total & & 1 \\
\hline
\end{tabular}

Perhitungan bobot sub kriteria akhir dengan Fuzzy AHP selesai, maka dilanjutkan dengan pengukuran performansi dengan metode Fuzzy TOPSIS. Berikut langkah Fuzzy TOPSIS :

(1) Melakukan pengubahan nilai crisp menjadi TFN, lalu merata-ratakannya dengan metode mean arithmatic.

(2) Menormalisasi penilaian. Tujuan dari menormalisasikan nilai TFN yaitu agar dapat berubah nilai dari skala 0 sampai dengan 1 . Dengan cara membagi nilai tersebut dengan nilai maksimum pada barisnya.

$r_{i j}=\left(\frac{a_{i j}}{c_{\bar{J}}}, \frac{b_{i j}}{c_{\bar{J}}}, \frac{c_{i j}}{c_{\bar{J}}}\right), j \in B$

(3) Menormalisasi terbobot. Maksud dari normalisasi terbobot yaitu mengalikan nilai bobot dengan nilai hasil normalisasi penilaian

$\mathrm{V}_{\mathrm{ij}}=\mathrm{wi}(.) \mathrm{rij}_{\mathrm{ij}}$

(4) Menentukan Nilai FPIS $\left(S^{+}\right)$dan FPNS $\left(S^{-}\right)$

$S^{+}=\left(\widetilde{v_{1}^{+}}, \widetilde{v_{2}^{+}}, \widetilde{v_{3}^{+}}, \ldots, \widetilde{v_{n}^{+}}\right)$

$S^{-}=\left(\widetilde{v_{1}^{-}}, \widetilde{v_{2}^{-}}, \widetilde{v_{3}^{-}}, \ldots, \widetilde{v_{n}^{-}}\right)$

(5) Menentukan nilai d (jarak solusi ideal), dapatkan dari menjumlahkan nilai setiap alternatif sedangkan didapatkan dari menjumlahkan nilai setiap alternatif sehingga didapatkan hasil seperti pada tabel 4 berikut : 
Tabel 4 Hasil Perhitungan Jarak Solusi Ideal Positif (d+) dan Solusi Ideal Negatif (d-)

\begin{tabular}{cccc}
\hline No & Nama Supplier & $\mathrm{d}+$ & $\mathrm{d}-$ \\
\hline 1 & Supplier 1 & 0,186 & 0,371 \\
2 & Supplier 2 & 0,239 & 0,332 \\
3 & Supplier 3 & 0,251 & 0,317 \\
4 & Supplier 4 & 0,254 & 0,286 \\
\hline
\end{tabular}

(6) Melakukan perhitungan Koefisien Kedekatan (CCi) setiap alternatif

$\mathrm{CCi}=\frac{d_{i}^{-}}{d_{i}^{+}+d_{i}^{-}} ; \mathrm{i}=1,2,3, \ldots, \mathrm{m}$

Tabel 5 Hasil Koefisien Kedekatan

\begin{tabular}{ccc}
\hline Ranking & Nama Supplier & CCi \\
\hline 1 & Supplier 1 & 0,666 \\
2 & Supplier 2 & 0,582 \\
3 & Supplier 3 & 0,558 \\
4 & Supplier 4 & 0,529 \\
\hline
\end{tabular}

CC (Coefficient Correlation) merupakan skala pengukuran performansi berdasarkan solusi ideal positif dan solusi ideal negatif. Berdasarkan perhitungan diatas, dapat dilihat nilai CCi 0,666 yaitu Supplier 1 mempunyai nilai terbesar yang menunjukkan solusi alternatif terbaik diantara empat supplier

\section{Simpulan}

Prioritas kriteria untuk pemilihan green supplier berdasarkan hasil perhitungan metode Fuzzy AHP adalah kualitas dengan bobot 0.216, sistem manajemen lingkungan dengan bobot 0.158 , fleksibilitas dengan bobot 0.135 , delivery dengan bobot 0.132 , green image dengan bobot 0.128 , dan biaya dengan bobot 0.126 merupakan prioritas kriteria dalam pemilihan green supplier. Sedangkan untuk prioritas sub kriteria yaitu jumlah penghargaan lingkungan dengan bobot 0.128, kadar zat PPM dengan bobot 0.114, metode pengelolaan limbah dengan bobot 0.106, indikator $\mathrm{pH}$ dengan bobot 0.091, potongan harga dengan bobot 0.086 , fleksibilitas pembayaran dengan bobot 0.074 , jenis instalasi pengolahan limbah dengan bobot 0.05 , pengiriman tepat jumlah dengan bobot 0.047, jumlah penerapan PERLING dengan bobot 0.045, harga bahan baku dengan bobot 0.04 , indikator warna dengan bobot 0.032 , ketepatan teknologi produksi dengan bobot 0.029 , penanganan pengiriman dengan bobot 0.022 , persentase rework dengan bobot 0,.021, dan fasilitas manufaktur dengan bobot 0.013, periode kontrak dan kemudahan koordinasi dengan bobot 0 . Performansi keseluruhan dari calon green supplier berdasarkan hasil perhitungan metode Fuzzy TOPSIS yaitu. Supplier 1 dengan nilai koefisien kedekatan sebesar 0.666, Supplier 2 dengan nilai koefisien kedekatan sebesar 0.582, Supplier 3 dengan nilai koefisien kedekatan sebesar 0.558 dan Supplier 4 dengan nilai koefisien kedekatan sebesar 0.529. Nilai koefisien kedekatan terbesar menunjukkan hasil solusi alternatif terbaik dan pada penelitian ini, Supplier 1 merupakan green supplier terbaik dengan nilai Koefisien kedekatan 0,666. 


\section{Referensi}

[1] I. Pujawan and E. Mahendrawathi, "Supply Chain Manajemen, Surabaya, Indonesia," ed: Gunawidya, Surabaya, 2010.

[2] J. Sarkis, "Manufacturing's role in corporate environmental sustainabilityConcerns for the new millennium," International Journal of Operations \& Production Management, vol. 21, pp. 666-686, 2001.

[3] R. E. Bellman and L. A. Zadeh, "Decision-making in a fuzzy environment," Management science, vol. 17, pp. B-141-B-164, 1970.

[4] T. L. Saaty, "The Analytical Hierarchy Process, Planning, Priority," Resource Allocation. RWS Publications, USA, 1980.

[5] S. H. Hashemi, A. Karimi, and M. Tavana, "An integrated green supplier selection approach with analytic network process and improved Grey relational analysis," International Journal of Production Economics, vol. 159, pp. 178-191, 2015.

[6] D.-Y. Chang, "Applications of the extent analysis method on fuzzy AHP," European journal of operational research, vol. 95, pp. 649-655, 1996.

[7] S.-J. Chen and C.-L. Hwang, "Fuzzy multiple attribute decision making methods," in Fuzzy Multiple Attribute Decision Making, ed: Springer, 1992, pp. 289-486. 